\title{
Without actors, there is no action: How interpersonal interactions help to explain routine dynamics
}

\author{
Anja Danner-Schröder ${ }^{1}$ (D)
}

Received: 30 March 2019 / Accepted: 13 July 2020 / Published online: 24 July 2020

(c) The Author(s) 2020

\begin{abstract}
In this paper, we argue that it is important to gain a better understanding on how people interact with each other to explain routine dynamics. Thus, we propose to focus on the interpersonal interactions of actors which is not only the fact that actors interact with each other but that the manner and quality of these interactions is important to understand routine dynamics. By drawing on social exchange theory, we propose a framework that seeks to explain routine dynamics based on different relationships between actors. Building on this framework, we provide different process models indicating how routine performing and patterning is enacted due to the respective relationship of actors. Our insights contribute to research on routine dynamics by arguing (1) that actions of patterning are dependent on the relationship of actors; (2) that trust works as an enabler for creating new patterns of actions; (3) that distrust functions as an enhancer for interrupting and dissolving patterns of actions.
\end{abstract}

Keywords Change · Interpersonal interactions · Interpersonal trust · Power asymmetries $\cdot$ Routine dynamics $\cdot$ Routine creation $\cdot$ Social exchange processes

JEL Classification M10

\section{Introduction}

"Without action, there is no routine" (Feldman et al. 2016: 506). Since the initiating work of Feldman and Pentland (Feldman 2000; Feldman and Pentland 2003) routine scholars are interested in performances enacted by actors to "look into the processes inside" (Dionysiou and Tsoukas 2013: 181). Focusing on actions helps to better understand the internal dynamics and structures of routines (Feldman 2000; Feldman and Pentland 2003). Moreover, by analyzing actions, routine insiders

Anja Danner-Schröder

anja.danner-schroeder@wiwi.uni-kl.de

1 Chair for Management Studies, Department of Business Studies and Economics, TU

Kaiserslautern, Gottlieb-Daimler-Straße 42, 67663 Kaiserslautern, Germany 
and outsiders can trace relations among actions and are able to identify patterns of actions (Feldman et al. 2016). Research on routines benefited from observing patterns of actions by pointing to routine dynamics, meaning routine stability, change and flexibility (see for example the studies in the special issue on routine dynamics in Organization Science 2016).

Without actors, there is no action. Even though the work on routine dynamics was initiated by stating that routines became a richer phenomenon "when we do not separate the people who are doing the routines from the routine" (Feldman 2000: 611) as they will "breathe life into the routines" (Feldman 2000: 627), we know surprisingly less about actors and how they contribute to routine dynamics, besides simply enacting them (Howard-Grenville 2005; Sargis-Roussel et al. 2017; Wright 2019). A few scholars have begun to focus on actors highlighting that people "are not interchangeable in the performance of routines, because they bring with them particular understandings and motivations" (Parmigiani and Howard-Grenville 2011: 437) and stressing the importance of "strengths and weaknesses of particular participants in the routines" (Feldman and Rafaeli 2002: 321). Moreover, Loch et al. (2013: 111) state, "the success of routines depends not only on their 'content' [...] but also on the social preferences that integrate the members". In line with this research, scholars mentioned that power dynamics, conflicts and relationships can shape routine change or stability (Lazaric and Denis 2005; Loch et al. 2013; Feldman and Pentland 2003; Pentland and Feldman 2005; Salvato and Rerup 2011, 2018; Sargis-Roussel et al. 2017; Turner and Rindova 2012; Zbaracki and Bergen 2010). However, none of those aspects has been explored in detail. By focusing solely on routine actions, the motivations and intentions behind actions get lost (Sargis-Roussel et al. 2017; Wright 2019).

Thus, we follow a recent call by Salvato and Rerup (2011: 475) to focus on interpersonal interactions of actors and by Loch et al. (2013) to examine how interpersonal interactions help to explain routine dynamics. With interpersonal interactions we mean not only the fact that actors interact with each other in order to accomplish an organizational routine, but that the manner and quality of these interactions is important to understand routine dynamics (Dutton and Heaphy 2003; Howard-Grenville 2005). Thus, our research question is the following one: How can interpersonal interactions help to explain routine dynamics?

To answer our research question, we draw on social exchange theory (Blau 1964) as one of "the most influential conceptual paradigms for understanding workplace behavior" (Cropanzano and Mitchell 2005: 874). Social exchange theorists argue that within social relationships individual behavior must be seen in relation to and as a response to behavior of the other one(s) (Blau 1964; Homans 1958) when "outcomes are based on a combination of parties' efforts" (Cropanzano and Mitchell 2005: 876). Drawing on this framework helps to develop a social exchange framework focusing on the interpersonal interactions of actors. According to social exchange theory individuals form distinct social exchange relationships with their respective counterpart. We use two widely studied social exchange processes to represent relationships within organizations: the formation of trust and the distribution of power (see Loch et al. 2013 for a similar approach in practice based routines research; Graen and Uhl-Bien 1995; Schoorman, Mayer, and Davis 2007; 
Cropanzano and Mitchell 2005; Weiler and Hinz 2019). Both aspects have also been under research in the literature on routine dynamics (see for example Dionysiou and Tsoukas (2013) for power; Feldman (2004) for trust and authority; Howard-Grenville (2005) for power and trust; Loch et al. (2013) for status and relationships).

In the following section, we review the role of actors on routine dynamics. This serves as a means of identifying the potential for further theoretical development. Second, we briefly introduce concepts of social exchange theory, which are the most relevant ones to the study of organizational routines. Following this, we propose and explain our social exchange framework that concentrates on the interpersonal interactions of actors and how these interactions drive routine dynamics. In the discussion section, we relate our social exchange framework to ongoing themes in the research of organizational routines, summarize the paper's main contributions, and suggest areas for future research.

\section{The role of actors on routine dynamics}

In recent years research on routine dynamics (Feldman 2000; Feldman and Pentland 2003; Feldman et al. 2016) has challenged the traditional understanding of organizational routines, in which agency is associated with the person who writes a standard operating procedure instead of the person enacting the routine (Feldman and Pentland 2003: 100). Feldman and Pentland (2003) proposed a new ontology of routines, taking agency explicitly into account. By drawing on Giddens' (1984) structuration theory, they conceptualized routines incorporating the duality of structure and agency. With the introduction of the practice-based routine understanding, scholars began to account for variation in routine performances and the interplay of stability and change (see the recent special issue in Organization Science 2016). Stability and change are enabled by performing actors who think, feel, and care and thus have the opportunity to produce variation (Feldman 2000). Moreover, motivation and intention of actors could drive routine dynamics (Dittrich and Seidl 2018; Feldman 2000; Howard-Grenville 2005).

Although research on routine dynamics emerged by paying attention to the performing actor, recent research called for making action more focal (Feldman et al. 2016; Feldman 2016; Pentland, Feldman, Becker, and Liu 2012). Feldman (2016: 38) even suggested theorizing the performative and ostensive aspects of routines as actions: performing and patterning. These calls to focus more on actions to analyze routines increasingly suppress the performing actors (Sargis-Roussel et al. 2017; Wright 2019). To refocus on the performing actor to explain routine dynamics, we first review how the actor has so far been theorized in routines research, thereby also outlining current shortcomings.

\subsection{Connections of actors and the (re)creation of a shared patterning}

Feldman and Rafaeli (2002) were first to contemplate that through enacting routines, connections between people are established based on interpersonal interactions. They 
defined connections as "interactions between people that enable them to transfer information" (Feldman and Rafaeli 2002: 312). Focusing on connections of actors helps to elevate on the role of actors in organizational routines. Connections provide knowledge about other actors of the routine, other members' tasks and perceptions of the routine. Hence, connections between actors of an organizational routine create a shared understanding. According to Dionysiou and Tsoukas (2013: 193) shared understandings imply not that individual schemata become identical, but that individual understandings are at minimum either compatible or congruent. This enables individuals to anticipate behavior of others, provides guidance how to behave and supports in interpreting information. Moreover, emerging ties between actors may be more positively or negatively evaluated compared to others. Shared understandings and the quality of the connections between actors are likely to influence how people act. Thus, shared understandings help either to maintain a pattern of actions or to adapt to variation in the environment (Feldman and Rafaeli 2002). Moreover, some variations are likely to occur because actors need to adapt their actions to other actors to whom they are connected (Feldman and Rafaeli 2002). Dionysiou and Tsoukas (2013), using a symbolic interactionist perspective (Mead 1934), have argued that actors identify themselves with the social activity in which they engage in, trying to determine what their counterparts are doing and matching their activities complementarily or congruently. By doing this, actors try to develop a shared understanding. Building on the importance of connections, Turner and Rindova (2012) revealed that team members' actions and understandings coalesce the longer team members work together, thus reducing variation. Sele and Grand (2016) went one step further by saying that connections between routines "are not automatic, but unfold in action" (734). In their study they indicated that actants can act either as intermediaries, merely maintaining connections, or as mediators, modifying connections between routines. Danner-Schröder and Geiger (2016) indicated in their study that the establishment of a shared understanding is an effortful enactment which can be reached through intensive rehearsals. Based on different rehearsal methods and differences in the codification of artifacts, the emerging shared understanding helped actors to orient their actions more towards stabilization or flexibility, according to the situation. Bucher and Langley (2016) revealed that by creating reflective spaces new connections could emerge that envisioned new ostensive patterns, whereas experimental spaces created connections to change performances. Bapuji et al. (2012) analyzed the influence of intermediaries as an exchange medium in interactions to create connections. Intermediaries are used to transmit the intentions of one actor to another. Thereby, the authors distinguished weak and strong routines, and found that actions and their expected responses by different actors meet less often across iterations in weak routines than in strong routines (Bapuji et al. 2012: 1590). Strong routines referred to routines staying rather stable across several iterations, whereas in weak routines variance could be observed.

\subsection{Conflicts between actors can be enacted through routines}

Whereas research stressing the importance of connections to support a shared understanding fostering either stability or change, other research demonstrated that the 
very same connections also have the potential for conflicts, meaning varying understandings that collide. For example, Zbaracki and Bergen (2010), as well as Salvato and Rerup (2018) illustrated that different groups within an organization (sales and marketing; designers and engineers) can in fact adhere to different understandings of a routine, which may result in conflicts as soon as these groups connect to engage in a routine. In the traditional understanding of routines (Cyert and March 1963) and in the "routine as truce" approach (Nelson and Winter 1982), conflicts and the enactment of routines are sequentially separated (Feldman 2016). In case a conflict emerges, it is resolved by establishing an agreement. An agreement builds a truce that stops conflicts for a certain period of time (Salvato and Rerup 2018). However, studies on routine dynamics have also shown that conflicts do not stop performances at all, instead conflicts can be enacted through routines (Feldman 2016). Routines are important for resolving conflicts to find new agreements (shared understandings). Whereas in the study by Zbaracki and Bergen (2010) the conflict could only be resolved by the vice president of the organization, in the case described by Salvato and Rerup (2018) the conflict was resolved through regulatory actions performed by individuals throughout the hierarchy. These regulatory actions created new connections between actors, which supported the creation of a dynamic truce (agreement) to accomplish conflicting goals (Salvato and Rerup 2018). Berente et al. (2016) demonstrated in their study of an ERP implementation at NASA that misalignment occurred when management and subordinates had different expectations of control. However, through dynamically adjusting routines the shock of everyday misalignments could be absorbed. In another study, Deken et al. (2016) revealed that different understandings could lead to a breakdown, which provided opportunities for routine work to generate novelty. Similarly, Danner-Schröder (2016) indicated that routines can be interrupted when team members' understandings of a routine vary widely. This can be resolved by changing the mode of practicing, thereby initiating a search for problem-solving alternatives.

\subsection{The influence of power and trust on routine dynamics}

Feldman and Pentland (2003) stated in their influential paper on the reconceptualizing of organizational routines, that power is an inevitable aspect of their theory. They suggested that the ostensive aspect is aligned with more dominant actors (managers) whereas the performative aspect is aligned with others, e.g. they resist and thus produce variation. Moreover, they revealed that managers are usually empowered to create routines, e.g. rules and artifacts. However if actors resist a rule and change their performance, it is again dependent on power, whether the exception turns into a rule or is ignored (Feldman and Pentland 2003). In an experimental study, Loch et al. (2013) discerned that stability and retention of routines depends on social integration. For example, the authors revealed that differentiated status within groups produces routine variance, as the influence of the high-status members is overweighted. Actors do not use these routines in their own decisions, which leads to inconsistent performances of groups. In contrast, groups with equal power use their routines more consistently and retain their routines in their individual decisions. In 
their study, Loch et al. (2013) also stated the usefulness of a collective agreement of routines to coordinate behavior, as for example status differences and bad relationships reduced the effectiveness with which a group developed a routine. Similar, Turner and Rindova (2012) disclosed that routine coalescing occurred within-crew teams, which reduced variance, whereas reconstituting of routines emerged across hierarchical levels to develop a common understanding of opportunities to change and modify routines. Dionysiou and Tsoukas (2013) stated that powerful actors are more able to alter a routine in the direction of their understanding than others. In contrast, actors with equal power will create a shared understanding of routines based on consensus. Dittrich et al. (2016) indicated that powerful actors are better able to participate in reflective talk, which might influence routine dynamics.

As outlined above, routines make connections among routine actors, which creates ties among these actors and a shared understanding. Based on this general argument, Feldman and Rafaeli (2002: 312) outlined, "the shared reliance on common resources leads to the development of mutual expectations about behavior, which is precisely the notion of 'trust' identified by network theorists." Moreover, some connections may be more trusted than other actors. Sargis-Roussel et al. (2017) indicated that social capital influences the repetition and predictability in the process of routines' emergence, in particular the pace of routines' emergence. Repeating similar sequences of actions increases the motivation to interact with each other based on growing trust that other actors will act predictable. Feldman (2004) showed that managers need to consider how change affects the availability of resources and fit to the work environment as they otherwise lose trust on the part of the employees.

\section{Social exchange theory}

Social exchange theorists argue that within social contexts individual behavior must be seen in relation to, and as a response to, behavior of the other one(s) (Blau 1964; Homans 1958) when "outcomes are based on a combination of parties' efforts" (Cropanzano and Mitchell 2005: 876). Social exchange processes are embedded in rather long-term social relationships in which individuals "tend to more strongly identify with the person or entity with which they are engaged" (Rupp and Cropanzano 2002: 926). Within our paper, we focus on social exchange relationships because we draw on the concept of routines as repetitive, continuous, and collective-and thus rather long-term-accomplishments in organizations (Dionysiou and Tsoukas 2013; Feldman and Pentland 2003).

Social exchange theory implies that individuals form distinct social exchange relationships depending on their counterpart, e.g. supervisor, coworker, subordinate, supplier, auditor, etc. (Cropanzano and Mitchell 2005; Flynn 2005). These exchange relationships differ in their quality as the endorsement of reciprocity can be different. An employee may, for instance, have high quality relationships with co-workers, but have at the same time a low quality relationship with his or her immediate supervisor (Cropanzano and Mitchell 2005). Perceptions of the respective relationship quality affect individual behavior towards counterparts (Masterson, Lewis, Goldman, and Taylor 2000) since individuals are supposed to reciprocate the help, 
advice, support, goodwill, and benefits they have received without negotiation and without knowing when the other one will return the goodwill (Blau 1964; Molm et al. 2000).

Social relationships within organizations may come in manifold guises and differ in various ways. To date, a huge variety of social exchange processes to represent relationships within organizations has been studied in the field of social exchange theory (e.g. helpfulness, felt obligation, positive mood, impulsivity, empathy, hostility, etc.; see Cropanzano and Mitchell 2005 for a review). All these social interactions to represent relationships and exchange processes within organizations are important. However, as the formation of trust and the distribution of power are widely accepted social exchange processes to represent relationships within organizations (Graen and Uhl-Bien 1995; Schoorman et al. 2007; Cropanzano and Mitchell 2005; Weiler and Hinz 2019), we decided to focus on those two.

\subsection{Interpersonal trust versus interpersonal distrust}

To analyze how interpersonal interactions help to explain routine dynamics we chose to include interpersonal trust to represent relationships and exchange processes within organizations (Fulmer and Gelfand 2012; Lewicki et al. 1998; Whitener et al. 1998). Rousseau et al. (1998) conceptualized trust as "a psychological state comprising the intention to accept vulnerability based upon positive expectations of the intentions or behavior of another" (p. 395). While this definition focuses on individual cognition, interpersonal trust from a dyadic perspective implies that both actors involved accept vulnerability, which is based upon the positive expectations of the intentions or behavior of the interaction partner (Klaussner 2012; Mayer et al. 1995; Schoorman et al. 2007). In other words, both individuals expect to be treated fairly within their relationship.

On the other end of the continuum, interpersonal distrust is opposed to interpersonal trust (Bigley and Pearce 1998). Distrust has been defined as "a lack of confidence in the other, a concern that the other may act so as to harm one, that he does not care about one's welfare or intends to act harmfully, or is hostile" (Govier 1994: 240). Thus, within a social relationship characterized by interpersonal distrust, individual actors either fear to be treated unfairly or have already experienced unfair treatment by their interaction partners. Distrust may even culminate in the exchange of incivility in both vertical (Klaussner 2014) and horizontal (Andersson and Pearson 1999) relationships.

\subsection{High power asymmetry versus low power asymmetry among interaction partners}

Within organizations, interpersonal relationships can be roughly differentiated in vertical (supervisor-subordinate) relationships (e.g. Sparrowe and Liden 1997) and horizontal (coworker) relationships (e.g. Deckop et al. 2003). The main feature distinguishing vertical from horizontal relationships is formal power (Astley and Sachdeva 1984). Power is understood as "the probability that one actor within a social relationship will 
be in a position to carry out his will despite resistance" (Weber 1978: 53). Supervisors are regularly equipped with formal power advantages (e.g. reward power, coercive power, etc., see French and Raven 1959; Yukl and Falbe 1990) over their immediate or more distant subordinates. Coworkers, in turn, are usually not equipped with the formal power that would enable them to direct and influence each other. However, informal power and status exists among coworkers (Thye 2000). Group members attribute informal leadership to those individuals who mostly comply with group norms or have gained appreciation from other group members, for instance, in return for extraordinary efforts or making personal sacrifices for the good of the group (Hollander 1958; Magee and Galinsky 2008; DeRue et al. 2015).

Within our paper, we draw on literature from both domains and distinguish relationships in terms of high power asymmetries and low power asymmetries. Seen from a relational perspective, power is based on structural relations and resides between actors (Fleming and Spicer 2014). Hence, power asymmetries are perceived from actors who either perceive to have more power or less power than the comparatively other one (Klaussner 2014). When power asymmetries are low, both interaction partners perceive each other as (rather) equal in terms of their opportunities to influence the other and/or the situation both individuals find themselves in. When power asymmetries are high, one interaction partner has systematic opportunities to influence the behavior of the other. High power asymmetries may emanate from unequally distributed formal power bases (e.g. Yukl and Falbe 1990), from informal roles and processes within groups (De Souza and Klein 1995; Wheelan and Johnston 1996), and existing status structures (Loch et al. 2013; Thomas-Hunt et al. 2003; Bendersky and Hays 2012).

Important to note for the purpose of our paper is that we do not assume that trust and power are "properties" of individuals that predict an outcome. As mentioned in the previous section, we follow a practice-based understanding of routines which focuses on performativity (Feldman and Orlikowski 2011; Feldman et al. 2016). Thus, relations are (re)constructed in interactions which means also trust and power are themselves (re-)created in interaction (see Wenzel et al. 2019, for a recent study that supports this argument). Moreover, power and trust are performed through routines, similar to conflicts as outlined above. For the purpose of this paper we assume that the relationship status (power asymmetry and trust) developed over time through performing the routine in the past. However, for analytical purposes, we assume the developed relationship quality remains rather stable for the time being (the time of analyzing routine dynamics). However, relationships can of course change over time and are not seen as separated from the routine, relationships are enacted though the routine.

\section{Interpersonal interactions driving routine dynamics: a social exchange framework}

Based on the two social interactions to represent relationships and exchange processes within organizations introduced above, we can differentiate four different relationships between actors. By outlining the different relationships and respective 
interpersonal interactions we show how routines are enacted differently. Dependent on the relationship, actions of patterning and performing can be enacted in different ways, which means that each of these relationships drives routine dynamics in a different way. To illustrate these processes in detail, we created a figure for each relationship and the respective process of enacting routine performing and patterning (see Figs. 1, 2, 3, 4). Hence, throughout the following sections, we will introduce each relationship from a social exchange perspective, relate them to routine processes, explain and describe the process of enacting routine performing and patterning and provide propositions.

\subsection{Social interactions based on a relationship of interpersonal trust and high power asymmetries: voluntary followership}

The first relationship is characterized by high levels of interpersonal trust with an asymmetric power distribution among actors. Cogliser et al. (2009) found that interpersonal trust positively affects subordinate performance, organizational commitment, and job satisfaction (see also Kashyap and Rangnekar 2016; Qing et al. forthcoming). Supervisors, in turn, are more likely to support their subordinates when they perceive their relationship quality as high (Scandura and Schriesheim 1994). Thus, both supervisor and subordinate "can count on each other" and perceive their relationship as a "mature partnership" (Graen and Uhl-Bien 1995: 230), reciprocating trust and support as inherent aspects of those relationships (Grant 2012; Uhl-Bien 2006). Both sides are not only willing to invest more than just economic resources, but are also loyal and even emotionally attached to each other. Consequently, in such relationships, followers trust their leader and are "willing to transcend self-interests for the sake of the collective (...), to identify with the vision articulated by the leader, to show strong emotional attachment to the leader, [and] to internalize the leader's values and goals" (Howell and Shamir 2005: 99) and voluntarily align their actions and understandings toward the more powerful actor. The leader, in turn, confides in his or her followers and respects them as valuable members of the team.

In light of organizational routines, we argue that patterns of actions change over time through interpersonal routine interactions of actors whose relationship is characterized by interpersonal trust and high power asymmetries by an alignment

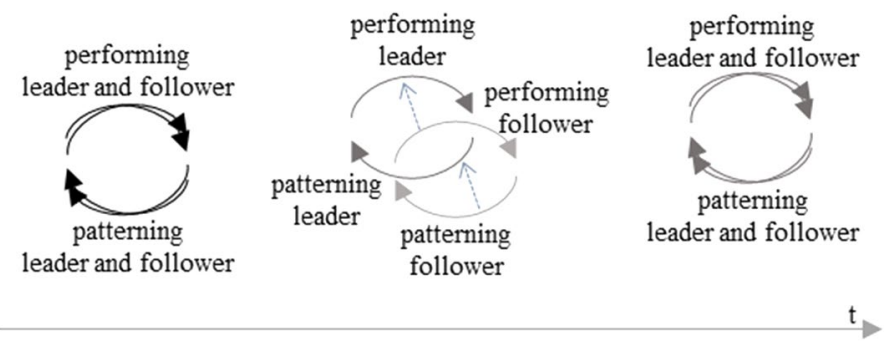

Fig. 1 The process of enacting routine performing and patterning based on voluntary followership 
process of actors' patterning and performing in the direction of the more powerful actor (see Fig. 1 for the process of enacting routine performing and patterning based on voluntary followership). Interpersonal trust implies that less powerful actors regard the actions of the more powerful actors in favor and do not question the motives behind the observed actions (Schoorman et al. 2007). For example, when more powerful actors enact a different pattern of action as in previous iterations, less powerful actors willingly adapt themselves to these patterns and act accordingly since they associate good reason for this adaptation based on a good, trusting working relationship. More precisely, actors who have less power voluntarily align their performing and patterning over time in belief that the more powerful one is acting with integrity and has good reasons for his ideas, perspectives, actions etc. (Brower et al. 2000; Howell and Shamir 2005) and thus the changed pattern of actions will have positive consequences (either for the organization or for the team). Kärreman et al. (2006) have pointed out that charismatic leadership supports this process. As opposed to other relationships, routine processes are fairly stable over time in case powerful actors set the standard and have a trustful relationship with their employees. Miller et al. (2012) suggest in their model that in a stable environment with a leader setting the tone, performances become increasingly patterned and efficient over time. Similar, Cohendet and Simon (2016) indicated that routines which are espoused and set in motion by powerful actors do not change frequently, thus they are easy to adapt for newcomers. Moreover, Cohendet and Simon (2016) demonstrated in their study that managers with authority prioritized efficiency over creativity. Managers are more concerned with controlling the process which cannot be ensured for creative steps in which the outcome is uncertain. Another reason that undermines creativity in situations of more powerful actors setting the standard and less powerful actors solely aligning their patterning and performing is that no discussions arise (Cast 2003). In such a relationship, supervisors do not expect open reflection and suggestions, they rather expect to set the tone themselves. In sum, routine change can occur based on a changed pattern of actions by the more powerful actor, but it is likely that it is initiated less frequently and is less innovative.

Proposition 1 Patterns of actions might change through interpersonal interactions in relationships of interpersonal trust and high power asymmetries as less powerful actors voluntarily adapt their performing and patterning according to more powerful actors who set the standard. Patterns of actions change less frequently and priority is given to efficiency instead of creativity.

\subsection{Social interactions based on a relationship of interpersonal trust and low power asymmetry: equal influence}

Low power asymmetry can typically be found within groups of formally equal members. According to temporal perspectives on group processes (Gersick 1988; Tuckman 1965), groups concentrate on their tasks when roles within the group have been adopted, standards have evolved, and group cohesiveness has begun to develop. From a social exchange perspective, trust is proposed to develop from 


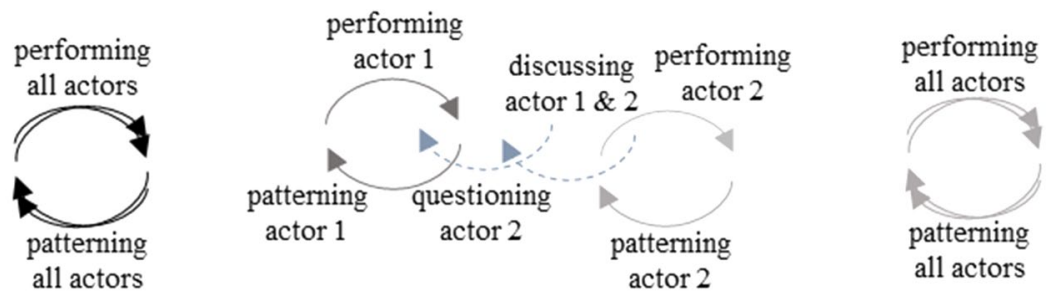

Fig. 2 The process of enacting routine performing and patterning based on equal influence

low, that is when groups are newly formed and initially confronted with tasks, to high, that is when roles and norms have been found and "group energy is channeled into the task" (Tuckman 1965: 396). Thus, when trust is high among group members, they are confident that their positive expectations in terms of others' actions and decisions will be returned in their favor (Lewicki et al. 1998). Consequently, along with variables such as group performance (Friedlander 1970), organizational citizenship behavior (McAllister 1995) and shared leadership (Pearce et al. 2010; Pearce et al. 2008) interpersonal trust has been found to have a positive effect on prosocial behaviors among group members (Brief and Motowidlo 1986; Cadenhead and Richiman 1996), effectiveness, creativity, and innovation (Wang et al. 2014). Interpersonal trust provides a foundation on which individual actors who are equal in terms of their power believe that the others care for the group's interests (Cook and Wall 1980) and will act with integrity (Robinson 1996; Weber and Carter 1998). Group members cooperate, support each other, and engage in joint problem solving when interpersonal trust is high (Dirks 1999). Thus, they are more willing to provide constructive feedback and engage in mutually encouraging exchange processes.

With regard to routine processes, we argue that patterns of actions change over time through interpersonal routine interactions of actors whose relationship is characterized by interpersonal trust and low power asymmetry by an alignment process of performing and patterning of all actors (see Fig. 2 for the process of enacting routine performing and patterning based on equal influence). Interpersonal trust makes an individual actor believe that the feedback he or she provides will be accepted by the other actor. In turn, feedback is easier to accept in relationships characterized by interpersonal trust (Rousseau et al. 1998). For example, when an actor enacts a pattern of actions differently compared to the last iteration, other actors might adapt their actions and understandings by asking questions or discussing the new pattern, also thinking of further innovative ideas based on a good, trusting working relationship. As Sonenshein (2016) illustrated in his study in the retailer industry, feedback served as an auxiliary routine, which helps to build up and alter a shared understanding. While high power asymmetry leads to the alignment of patterning toward the perspective of the powerful actors, in relationships of low power asymmetry, involved actors are proposed to more openly and recursively reflect on their 
understandings, ideas, actions and possible consequences. They are more likely to listen to each other, discuss pros and cons and thereby adjust and align their patterning. Thereby, interpersonal trust within groups of equal influence leads to more creative and innovative processes of routine change (Wang et al. 2014) because it "allows participants to step out of existing discursive and cognitive structures and routines and experiment with tentative new ideas that may challenge the existing orientations" (Jarzabkowski and Seidl 2008: 1405). Bucher and Langley (2016) exemplified that less hierarchical teams are more creative as they exchange ideas more openly in reorienting routine dynamics (see also Yoon et al. 2016). Similarly, Cohendet and Simon (2016) indicate that teams without power inequality are more creative as they also have more fun. In other words, mutual feedback and reflective discussions enable actors to align their expectations and understandings of the pattern of actions (Dirks 1999). Compared to relationships of interpersonal trust and high power asymmetry, the alignment of patterning is proposed to take longer, because there is no single guiding actor and "building consensus takes time" (Bourgeois III and Eisenhardt 1988: 818). Bucher and Langley (2016) indicated in their study of hospital change, that in teams without power differences it can be difficult to take decisions which in the end takes more time than expected. Actors involved in the routine are of equal influence on how the routine is understood, performed, and changed. They share the responsibility for the routine enactment (Pearce et al. 2008; Wang et al. 2014).

Proposition 2 Patterns of actions might change through interpersonal interactions in relationships of interpersonal trust and low power asymmetries as all actors are open to align their performing and patterning of the routine towards the other actors' performing and patterning. Routine change will take more time but is also more creative and innovative.

\subsection{Social interactions based on a relationship of interpersonal distrust and high power asymmetry: surface acting}

Distrust in relationships (Kramer 1999) is understood as a concern that the other actor will not act in one's best interests, may act to harm or even engage in potentially injurious behavior (Govier 1994; Lewicki et al. 1998). Leadership scholars have begun to take these concerns into account (Tepper 2007) and have

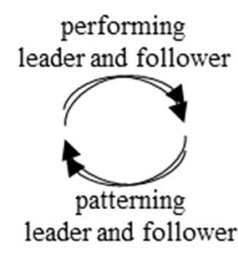

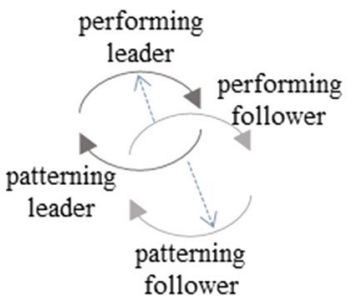

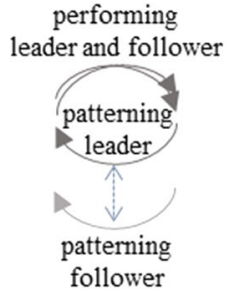

Fig. 3 The process of enacting routine performing and patterning based on surface acting 
acknowledged that perceptions of distrust may come along or result from perceptions of injustice within organizational relationships (Lavelle et al. 2007), especially in supervisor-subordinate relationships (Chan and McAllister 2014; Klaussner 2014). Such perceptions have been shown to have negative effects on organizational commitment, work satisfaction, and self-esteem (Aryee et al. 2007; Burton and Hoobler 2006; Kashyap and Rangnekar 2016; Qing et al. forthcoming; Tepper 2000). Thus, in relationships characterized by distrust, those who have less power perceive high levels of psychological distress and increasingly withdraw from their work and from those who have more power (Chan and McAllister 2014; Chi and Liang 2013; Colquitt et al. 2001; Tepper et al. 2007). Those who have more power, in turn, supposedly perceive such withdrawal reactions as inadequate and may in response even increase their pressure, which can further intensify perceptions of distrust and injustice (Klaussner 2014).

In addition, power has been shown to decrease reflective abilities of those who perceive themselves as having more power than the other (Cast 2004). In other words, the higher the asymmetries in power, the lower the perspective-taking abilities of the one with more power (Fiske 1993; Keltner and Robinson 1997). Highly powerful actors are often unable to accept critical upward feedback (Judge et al. 2009), because "with power often comes excessive pride and arrogance" (Kets de Vries 1990: 752). Thus, power is negatively related to empathic abilities. Consequently, powerful actors rather define the situation instead of discussing different perspectives and opinions (Cast 2003). Less powerful actors comply with the expectations of the more powerful actors because they fear the negative consequences that may follow if they resist (Harlos 2010; Lewicki et al. 1998; Tripp et al. 2007). Thus, they engage in surface acting (Hu and Shi 2015) by showing expected behavior and displaying emotions that do not match their true inner feelings (Carlson et al. 2012; Zapf 2002).

In light of routine processes, we argue that patterns of actions in interpersonal routine interactions of actors whose relationship is characterized by interpersonal distrust and high power asymmetry seem to be aligned even though the patterning of actors vary (see Fig. 3 for the process of enacting routine performing and patterning based on surface acting). From the outside, one could believe that less powerful actors align their performing according to the actions and understandings of more powerful actors, similar to relationships of high power asymmetry and interpersonal trust. However, the underlying motivation is quite different here since adaptation of performing and patterning does not occur voluntarily. It rather occurs because actors in a significantly less powerful position feel forced to align their actions out of fear of negative consequences, even if they do not share the same understanding. In case less powerful actors would critically reflect on or even reject pattern of actions of more powerful actors (Harlos 2010; Tripp et al. 2007) they would risk to be sanctioned (Lewicki et al. 1998; Tepper 2007). Consequently, less powerful actors engage in surface acting-they align their actions superficially-without adapting their personal understanding of the routine. Hence, changing patterns of actions are also not as creative and innovative as in constellations including trust, because on the one hand reflective abilities decrease of those having more power (Cast 2004), and on the other hand, fearing negative consequences prevents creative 
processes. Moreover, surface acting may result in diminished job satisfaction (Bhave and Glomb 2016), high levels of exhaustion, and work withdrawal (Chi and Liang 2013). When less powerful actors increasingly withdraw from the routine performance while holding different understandings about what the routine should actually be like, exerting power seems to be the only way of maintaining the pattern of action. Thus, routine performance is solely based on the expectations set by the powerful routine actors (Cast 2003). In consequence, the routine itself is much more fragile than in both relationships of interpersonal trust discussed above.

Proposition 3 Patterns of actions seem to be aligned on the surface through interpersonal interactions in relationships of interpersonal distrust and high power asymmetries as less powerful actors involuntarily adapt their performing to the understandings of more powerful actors to avoid negative consequences. Changing patterns of actions will be less creative and innovative compared to relationships of trust.

\subsection{Social interactions based on a relationship of interpersonal distrust and low power asymmetry: conflicting views}

Distrust may also characterize relationships of actors who are rather equal in terms of their power. Negative reciprocity has been intensively addressed in group conflict literature (Jehn and Mannix 2001; Simons and Peterson 2000). Jehn and Mannix (2001: 238), for instance, found that relationship conflictsdefined as "personal issues such as dislike among group members and feelings such as annoyance, frustration, and irritation"-have negative effects on group performance. From a social exchange perspective, strong relationship conflicts in groups are characterized by interpersonal distrust (Jehn 1995) and go hand in hand with reductions in commitment, high levels of psychological distress, and even anxiety resulting in group withdrawal (Jehn and Mannix 2001; Staw et al. 1981). Relationship conflicts have been shown to induce sinister attributions to other individuals' behavior. When behavior of the other one is perceived as rude or inadequate on the relationship level of workplace communication, an incivility spiral might be triggered, leading eventually to the exchange of highly aggressive behaviors (Andersson and Pearson 1999). Thus, high levels of interpersonal
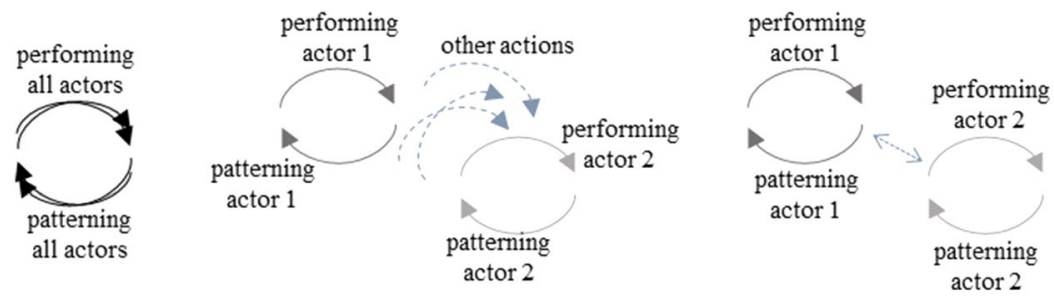

Fig. 4 The process of enacting routine performing and patterning based on conflicting views 
distrust disrupt task-oriented behavior in groups because group members are fully concerned with their conflicts (Simons and Peterson 2000). Individuals rather combat each other than cooperate with each other.

With regard to routine processes, we argue that patterns of actions in interpersonal routine interactions of actors whose relationship is characterized by interpersonal distrust and low power asymmetry are difficult to align between actors as patterning of actors vary (see Fig. 4 for the process of enacting routine performing and patterning based on conflicting views). Routine actors are more concerned with their interpersonal conflicts than with the routine enactment per se; hence, they are highly distracted from their routine tasks. In such cases, actors may be engaged with more self-defensive behaviors, and with securing their own status and position. In other words, when negative behavior is exchanged (within the range of minor incivility to expressions of workplace aggression), the routine as a collective accomplishment gets eclipsed. The routine enactment as such gets exploited and misused as a stage on which group conflicts are acted out. Thus, over time, variation in performing is not the result of a change process, instead variation is rather the result of actions that are not even part of the routine and might not be intended to solve the conflict. Instead, the routine might even get completely disrupted when the group is neither able to come to a joint solution nor able to stick to the existing routine because the actors involved are constantly concerned with devaluing, harming, and sabotaging each other whenever they meet (Andersson and Pearson 1999). In this case, performing and patterning can hardly be aligned.

Proposition 4 Patterns of actions are difficult to align through interpersonal interactions in relationships of interpersonal distrust and low power asymmetries as the alignment of actors' performing and patterning is inhibited. Specifically, distrust distracts actors from the routine performance and enables disruptive actions, eventually leading to routine dissolution.

\section{Discussion}

The purpose of this this paper has been to tease out how interpersonal interactions among routine actors help to explain routine dynamics. To explore this purpose in depth, we drew on social exchange theory to understand the interaction processes among actors, or more precisely, to understand the individual behavior of actors in relation to, and as a response to the behavior of the other one (Blau 1964; Homans 1958). By building on these insights, we argue that actions of patterning are dependent on the respective relationship of actors, trust works as an enabler for creating new pattern of actions, and distrust functions as an enhancer for interrupting and dissolving patterns of actions. 


\subsection{Actions of patterning dependent on the relationship of actors}

Our framework suggests going beyond the 'simple' explanation of how an aligned understanding emerges based on connections (Bapuji et al. 2012; Feldman and Rafaeli 2002; Sele and Grand 2016; Turner and Rindova 2012) as well as extends beyond the necessity of aligning actions (Danner-Schröder 2016; Danner-Schröder and Geiger 2016; Dionysiou and Tsoukas 2013; Feldman and Rafaeli 2002; Turner and Rindova 2012; Zbaracki and Bergen 2010) as an indispensable aspect of actors being able to understand each other's actions (Dionysiou and Tsoukas 2013). Our approach highlights that connections can be very different, meaning actors have different relationships to their respective counterparts. Dependent on these relationships, actions of patterning can be enacted in different ways. By pointing to these insights we answer a call made just recently by Feldman (2016: 39) that an important question routine researchers should answer is "How do we do patterning". This question is even more relevant after one actor has tried to change a pattern of actions as this change might also entail a change in the patterning process of actors.

In relationships characterized by high power asymmetry, alignment processes are a one-way process. This means that actors with less power are expected to align their actions and understandings in the process of patterning with those of more power (Cast 2004; Dionysiou and Tsoukas 2013). Following this line of thought, previous research suggests that aligned understandings emerge based on the assumption that the less powerful actor will adapt to the expectations of the more powerful actor (Dionysiou and Tsoukas 2013). Our research contributes to this debate by illuminating the importance of understanding why less powerful actors try to align their actions and further emphasizes that this does not necessarily lead to an aligned process of patterning. In relationships of trust, less powerful actors follow voluntarily the patterning of the more powerful actor based on the assumption that she or he is acting with good intentions (see Fig. 1). In contrast, in relationships of distrust, less powerful actors behave in accordance to the expectations of more powerful actors as they fear negative consequences if actions stray from the expected pattern of actions (Harlos 2010; Tripp et al. 2007). Hence, to avoid possible negative consequences, they align their actions according to the pattern of actions enacted by the more powerful actor. However, these aligned actions are enforced by power advantages and are not enacted based on joint decisions or agreements. On the one hand, nevertheless, in the process of patterning less powerful actors might align their understandings according to the expectations set by the more powerful actors over time. In this case, they adjust their understanding in the direction of the more powerful actors (Dionysiou and Tsoukas 2013) and an aligned pattering process emerges. On the other hand, less powerful actors can easily act as expected to, even if they have a different understanding of the routine. This implies that they engage in surface acting, which means that they seem to comply with the expectations from the more powerful actors (Carlson et al. 2012; Hu and Shi 2015), but the patterning process is not aligned (see Fig. 3).

In relationships characterized by trust and low power asymmetry, one actor changes performing an expected pattern of actions. The other actors perceive this new performing in good will and the following process of patterning is an open 
discussion and questioning (Dirks 1999) of the new pattern of actions. Thus, the specific actions involved in creating a pattern of patterning (Feldman 2016) are talking to each other and exchanging ideas in an open process. Over time, also creative new actions might be enacted in a trial-and-error process to find innovative new ways of performing and patterning. The process of patterning might take longer as actors have equal influence on the process of patterning (see Fig. 2), but might also be more innovative.

In relationships characterized by distrust and low power asymmetry, a mutual patterning process does not take place due to conflicting views. Actors perform other actions that have very little or even nothing to do with performing the routine (Andersson and Pearson 1999). These actions do not lead to creating a new performing or a shared patterning, instead performing and patterning of different actors are further away from each other than they were before (see Fig. 4). The further away actors are in their expectations, the more likely it is that patterns of actions disrupt.

\subsection{Trust as an enabler for creating new patterns of actions}

Recent research on routine dynamics stresses the possibility of routine change and stability, as "each time a routine is enacted is an occasion for variation" (Feldman et al. 2016: 508). Moreover, this research seems to assume, that each actor involved in performing a routine has the opportunity to produce variation. However, from an organizational point of view, we also know that changing a pattern of actions might be seen as rule-breaking and thus might be sanctioned (Geiger and Schröder 2014; Reynaud 2005). Following this, not each actor might be in the situation to change a pattern of actions without fearing negative consequences due to breaking a rule as behavioral expectation. Moreover, Feldman and Pentland (2003) theorize that it is dependent on power if a new pattern of action turns into a rule or will be ignored.

Our social exchange framework indicates that trust is an enabler for routine actors to change a pattern of actions, as a trusting relationship reduces the fear of negative reactions. Being that counterparts-either less powerful actors in groups with high power asymmetry or actors within a group of equal power distribution - are in such groups open to variation (since variation is perceived in good will), actors within the same group can depart from the prior pattern of actions without having to fear negative consequences. In a trustful relationship, actors depart from previous routine actions knowing that their counterparts would first think of the performance variation before sanctioning it. Thus, actors feel safe to create a new pattern of actions departing from the old pattern of actions. On the other hand, actors observing the performance variation perceive these actions as favorable, and in turn do not question the actions or intentions of the change per se because they trust their respective counterpart. Thus, trustful feedback and discussions (Dirks 1999) further encourage an open reflection of the new pattern of actions. This can result in changes in patterns of actions or in a confirmation of prior patterns of actions in accordance with the context level, e.g. organizational rules and culture (Geiger and Schröder 2014; Howard-Grenville 2005). 
Moreover, our approach indicates that actors whose relationship is characterized by trust and low power asymmetries are superior in producing novelty, creativity and innovation. Actors with authority prioritize efficiency instead of novelty and creativity (Cohendet and Simon 2016) and set the standard instead of discussing alternatives. Exchanging ideas in an trustful, open culture and having fun while discussing ideas are important for creative, new ideas (Bucher and Langley 2016; Cohendet and Simon 2016). Accepting feedback and providing feedback help in renegotiating and altering routine understandings and actions towards creative and innovative ideas (Sonenshein 2016). In the study by Cohendet and Simon (2016: 622) the producer received "a strong message of trust" which enabled him to reflect honestly upon the previous process of developing games which was a failure. Based on this reflection the producer received the freedom to create a new process to develop games.

In sum, whereas previous research has stressed that actors trusting each other believe that the other one will act predictable (Sargis-Roussel et al. 2017), our social exchange framework highlights that actors are more likely to create new patterns of actions in case they have a trustful relationship as they feel safe without fearing negative consequences.

\subsection{Distrust as enhancer for interrupting and dissolving patterns of actions}

Our research suggests that interactions among actors do not necessarily lead to mutual processes of patterning. Quite the contrary, exchange processes of actors may also result in misunderstandings that end in surface acting or action patterns that vary from former patterns of actions.

Conflicts are an integral part of routines and can be enacted through routines. As research has shown, conflicting goals in organizational routines might lead to a conflict of different departments or routine participants (Salvato and Rerup 2018; Zbaracki and Bergen 2010). Whereas in the study by Salvato and Rerup (2018) the conflict was resolved through regulatory actions enacted by individuals throughout the hierarchy, in the study by Zbaracki and Bergen (2010) the conflict could only be resolved in the hierarchy. So one reason to solve conflicts is escalating it in the hierarchy. Another one is regulatory actions which means either recombinating activities and participants (splicing), switching on particular activities and participants (activating) or switching off particular activities and participants (repressing). In all scenarios, actors are in need to work together, often times in new constellations to facilitate multivocality and inclusion (Salvato and Rerup 2018). Our research suggests that in case actors have worked together in previous situations trustful relationships might have evolved. Conflicts can be solved more effectively in situations in which actors work together in a trustful relationship as agreements might be easier to find.

In the case of actions diverging from previous pattern of actions due to different understandings, it is important to note that these performance variations, as previous research has impressively shown, are not (necessarily) in favor of optimizing or improving the routine process (Bucher and Langley 2016; Deken et al. 2016; Feldman 2000; Howard-Grenville 2005; Turner and Rindova 2012). Such variation 
can also be the outcome of interpersonal exchange processes built on distrust. We argue that interpersonal distrust within vertical and horizontal relationships distracts actors from their tasks (Simons and Peterson 2000) because they are concerned with their relationship conflicts. In such situations, actors might engage in self-defensive behaviors to secure their status and position, which can result in actions that have very little or even nothing to do with the routine process per se, e.g. devaluing and sabotaging others (Andersson and Pearson 1999). Due to these actions not belonging to the routine per se, the routine process can be delayed or interrupted. This is why other actors do not understand these actions and realize that they are not part of the routine; thus, they do not know how to continue (Danner-Schröder 2016). In extreme cases, this can even end in the dissolution of a pattern of actions.

\section{Implications for further research}

Our discussion around interpersonal interactions is meant to open up new directions for further research. We proposed the introduction of power in terms of formal and informal manifestations. The paper also suggested that actors might not enact a mutual process of patterning, which may result in behavior that has little or almost nothing to do with the routine as such. This could enable further research in trying to integrate the discussion around micro politics (Burns 1961) with research on routines. In case of micro politics, actors might also engage in actions that are not part of the pattern of actions to manipulate routine understandings and interpretations. Thereby the research of Dionysiou and Tsoukas (2013) pointing to the use of information collected through role taking, from the less powerful actors about more powerful actors, can be integrated. It could thereby be interesting to evaluate these consequences on routine dynamics.

Our research focuses especially on interpersonal interactions between human actors. However, interactions between human and non-human actors shape our lives more and more (Glaser 2017; Sele and Grand 2016). Hence, routine performances are not only enacted by human actors, but also by non-human ones, such as robots and machines. The question whom to trust, e.g. humans, non-humans, machines, algorithms, developers or designers deserves further exploration. As trust is a human capability, in times of increasing use of non-human actors these questions might be highly relevant.

Another aspect that leaves room for further research is our sole focus on trust and power asymmetries. However, investigating other social exchange processes representing relationship qualities would be worth elaborating on, such as mutual respect, support, obligation or liking could also be of relevance. Empirical research could focus on these social exchange processes and inductively add other possible processes as well as their consequences on routine dynamics.

Moreover, the development of relationships through the enactment of routines is not integrated in our framework. Thus, future research could explore how relationships are enacted through routines. In this sense, it might be also interesting to focus on other relationships outside the organization, as our paper was focusing on social 
relationships within organizations, such as routines between an organization and its customers (Turner and Rindova 2012).

In conclusion, our framework proposes underlying mechanisms of routine stability and change, and even routine interruptions and dissolution. A necessary next step is to empirically explore exchange processes among actors' in particular organizational contexts to develop a deeper understanding of organizational routines. On a more general level, we hope our framework will direct future research toward interpersonal interactions, concentrating on exchange processes among actors to account for routines dynamics.

Acknowledgements Open Access funding provided by Projekt DEAL. The author is grateful for the support during the review process by Ralf Ewert and the comments of two anonymous reviewers who helped in advancing the paper. The author is also grateful to Stefan Klaußner, Daniel Geiger and Gordon MüllerSeitz for helpful feedback, which significantly helped in shaping the contribution of this paper.

Funding This research received no specific grant from any funding agency in the public, commercial, or not-for-profit sector.

\section{Compliance with ethical standards}

Conflict of interest The author declares that she has no conflict of interest.

Open Access This article is licensed under a Creative Commons Attribution 4.0 International License, which permits use, sharing, adaptation, distribution and reproduction in any medium or format, as long as you give appropriate credit to the original author(s) and the source, provide a link to the Creative Commons licence, and indicate if changes were made. The images or other third party material in this article are included in the article's Creative Commons licence, unless indicated otherwise in a credit line to the material. If material is not included in the article's Creative Commons licence and your intended use is not permitted by statutory regulation or exceeds the permitted use, you will need to obtain permission directly from the copyright holder. To view a copy of this licence, visit http://creativecommons.org/licen ses/by/4.0/.

\section{References}

Andersson L, Pearson C (1999) Tit for tat? The spiraling effect of incivility in the workplace. Acad Manag Rev 24:452-471

Aryee S, Chen ZX, Sun L-Y, Debrah YA (2007) Antecedents and outcomes of abusive supervision: test of a trickle-down model. J Appl Psychol 92:191-201

Astley WG, Sachdeva PS (1984) structural sources of intraorganizational power: a theoretical synthesis. Acad Manag Rev 9:104-113

Bapuji H, Hora M, Saeed AM (2012) Intentions, intermediaries, and interaction: examining the emergence of routines. J Manag Stud 49:1586-1607

Bendersky C, Hays NA (2012) Status conflict in groups. Organ Sci 23:323-340

Berente N, Lyytinen K, Yoo Y, King JL (2016) Routines as shock absorbers during organizational transformation: integration, control, and NASA's enterprise information system. Organ Sci 27:551-572

Bhave DP, Glomb TM (2016) The role of occupational emotional labor requirements on the surface acting-job satisfaction relationship. J Manag 42:722-741

Bigley GA, Pearce JL (1998) Straining for shared meaning in organization science: problems of trust and distrust. Acad Manag Rev 23:405-421

Blau PM (1964) Exchange and power in social life. John Wiley \& Sons, New York

Bourgeois LJ III, Eisenhardt KM (1988) Strategic decision processes in high velocity environments: four cases in the microcomputer industry. Manage Sci 34:816-835 
Brief AP, Motowidlo SJ (1986) Prosocial organizational behaviors. Acad Manag Rev 11:710-725

Brower HH, Schoorman FD, Tan HH (2000) A model of relational leadership: the integration of trust and leader-member exchange. Leadersh Quart 11:227-250

Bucher S, Langley A (2016) The interplay of reflective and experimental spaces in interrupting and reorienting routine dynamics. Organ Sci 27:594-613

Burns T (1961) Micropolitics: mechanisms of institutional change. Adm Sci Q 6:257-281

Burton JP, Hoobler JM (2006) Subordinate self-esteem and abusive supervision. J Manag Issues 18:340-355

Cadenhead AC, Richiman CL (1996) The effects of interpersonal trust and group status on prosocial and aggressive behaviors. Soc Behav Personal 24:169-184

Carlson D, Ferguson M, Hunter E, Whitten D (2012) Abusive supervision and work-family conflict: the path through emotional labor and burnout. Leadersh Q 23:849-859

Cast AD (2003) Power and the ability to define the situation. Soc Psychol Q 66:185-201

Cast AD (2004) Role-taking and interaction. Soc Psychol Q 67:296-309

Chan ME, McAllister DJ (2014) Abusive supervision through the lens of employee State Paranoia. Acad Manag Rev 39:44-66

Chi S-CS, Liang S-G (2013) When do subordinates' emotion-regulation strategies matter? Abusive supervision, subordinates' emotional exhaustion, and work withdrawal. Leadersh Q 24:125-137

Cogliser C, Schriesheim CA, Scandura TA, Gardner WL (2009) Balance in leader and follower perceptions of leader-member exchange: relationships with performance and work attitudes. Leadersh Q 20:452-465

Cohendet PS, Simon LO (2016) always playable: recombining routines for creative efficiency at Ubisoft Montreal's video game studio. Organ Sci 27:614-632

Colquitt JA, Conlon DE, Wesson MJ, Porter COLH, Ng KY (2001) Justice at the millenium: a metaanalytic review of 25 years of organizational justice research. J Appl Psychol 86:425-445

Cook J, Wall T (1980) New work attitude measures of trust, organizational commitment, and personal need fulfillment. J Occup Psychol 53:39-52

Cropanzano R, Mitchell MS (2005) Social exchange theory: an interdisciplinary review. J Manag 31:874-900

Cyert RM, March JG (1963) A behavioral theory of the firm. Englewood Cliffs, New Jersey

Danner-Schröder A (2016) Routine dynamics and routine interruptions: how to create and recreate recognizability of routine patterns. Managementforschung 26:63-96

Danner-Schröder A, Geiger D (2016) Unravelling the motor of patterning work: toward an understanding of the microlevel-dynamics of standardization and flexibility. Organ Sci 27:633-658

De Souza G, Klein HJ (1995) Emergent leadership in the group goal-setting process. Small Group Res 26:475-496

Deckop JR, Cirka CC, Andersson LM (2003) Doing unto others: the reciprocity of helping behavior in organizations. J Bus Ethics 47:101-114

Deken F, Carlile PR, Berends H, Lauche K (2016) Generating novelty through interdependent routines: a process model of routine work. Organ Sci 27:659-677

DeRue DS, Nahrgang JD, Ashford SJ (2015) Interpersonal perceptions and the emergence of leadership structures in groups: a network perspective. Organ Sci 26:1192-1209

Dionysiou D, Tsoukas H (2013) Understanding the (re)creation of routines from within: a symbolic interactionist perspective. Acad Manag Rev 38:181-205

Dirks KT (1999) The effects of interpersonal trust on work group performance. J Appl Psychol $84: 445-455$

Dittrich K, Seidl D (2018) Emerging intentionality in routine dynamics: a pragmatist view. Acad Manag J 61:111-138

Dittrich K, Guérard S, Seidl D (2016) Talking about routines: the role of reflective talk in routine change. Organ Sci 27:678-697

Dutton JE, Heaphy E (2003) The power of high quality connections. In: Cameron K, Dutton JE, Quinn RE (eds) Positive organizational scholarship. Berrett-Koehler, San Francisco, pp 263-278

Feldman M (2000) Organizational routines as a source of continuous change. Organ Sci 11:611-629

Feldman M (2004) Resources in emerging structures and processes of change. Organ Sci 15:295-309

Feldman M (2016) Routines as process: Past, present and future. In: Howard-Grenville J, Rerup C, Langley A, Tsoukas H (eds) Organizational routines: How they are created, maintained, and changed. Oxford, UK, Oxford University Press, Perspectives on process organization studies, pp 23-46

Feldman M, Orlikowski WJ (2011) Theorizing practice and practicing theory. Organ Sci 22:1240-1253 
Feldman M, Pentland BT (2003) Reconceptualizing organizational routines as a source of flexibility and change. Adm Sci Q 48:94-118

Feldman M, Rafaeli A (2002) Organizational routines as sources of connections and understandings. J Manag Stud 39:309-331

Fleming P, Spicer A (2014) Power in management and organization science. Acad Manag Ann 8(1):237-298

Feldman M, Pentland BT, D’Adderio L, Lazaric N (2016) Beyond routines as things: introduction to the special issue on routine dynamics. Organ Sci 27:505-513

Fiske ST (1993) Controlling other people: the impact of power on stereotyping. Am Psychol 48:621-628

Flynn FJ (2005) Identity orientations and forms of social exchange in organizations. Acad Manag Rev 30:737-750

French JRP, Raven B (1959) The bases of social power. In: Cartwright D (ed) Studies in social power. University of Michigan, Ann Arbor, pp 150-167

Friedlander F (1970) The primacy of trust as a facilitator of further group accomplishment. J Appl Behav Sci 6:387-400

Fulmer CA, Gelfand MJ (2012) At what level (and in whom) we trust: trust across multiple organizational levels. J Manag 38:1167-1230

Geiger D, Schröder A (2014) Ever-changing routines? Toward a revised understanding of organizational routines between rule-following and rule-breaking. Schmalenbach Bus Rev 66:170-190

Gersick C (1988) Time and transition in work teams: toward a new model of group development. Acad Manag J 31:9-41

Giddens A (1984) The constitution of society. Cambridge University Press, Cambridge

Govier T (1994) An epistemology of trust. Int J Moral Soc Stud 8:155-174

Graen GB, Uhl-Bien M (1995) Relationship-based approach to leadership: development of leader-member exchange (LMX) theory of leadership over 25 years: Applying a multi-level multi-domain perspective. Leadersh Quart 6:219-247

Glaser V (2017) Design performances: How organizations inscribe artifacts to change routines. Acad Manag J 60(6):2126-2154

Grant AM (2012) Leading with meaning: beneficiary contact, prosocial impact, and the performance effects of transformational leadership. Acad Manag J 55:458-476

Harlos KP (2010) If you build a remedial voice mechanism, will they come? Determinants of voicing interpersonal mistreatment at work. Hum Relat 63:311-329

Hollander EP (1958) Conformity, status, and idiosyncrasy credit. Psychol Rev 65:117-127

Homans GC (1958) Social behavior as exchange. Am J Sociol 63:597-606

Howard-Grenville JA (2005) The persistence of flexible organizational routines: the role of agency and organizational context. Organ Sci 16:618-636

Howell JM, Shamir B (2005) The role of followers in the charismatic leadership process: relationships and their consequences. Acad Manag Rev 30:96-112

Hu X, Shi J (2015) Employees' surface acting in interactions with leaders and peers. J Organ Behav 36:1132-1152

Jarzabkowski P, Seidl D (2008) The role of meetings in the social practice of strategy. Organ Stud 29:1391-1426

Jehn K (1995) A multimethod examination of the benefits and detriments of intragroup conflict. Adm Sci Q 40:256

Jehn K, Mannix E (2001) The dynamic nature of conflict: a longitudinal study of intragroup conflict and group performance. Acad Manag J 44:238-251

Judge TA, Piccolo RF, Tomek K (2009) The bright and dark sides of leader traits: a review and theoretical extension of the leader trait paradigm. Leadersh Q 20:855-875

Kärreman D, Alvesson M, Wenglen R (2006) The charismatization of routines: management of meaning and standardization in an educational organization. Scand J Manag 22:330-351

Kashyap V, Rangnekar S (2016) Servant leadership, employer brand perception, trust in leaders and turnover intentions: a sequential mediation model. RMS 10:437-461

Keltner D, Robinson RJ (1997) Defending the status quo: power and bias in social conflict. Pers Soc Psychol Bull 23:1066-1077

Kets de Vries MFR (1990) The organizational fool: balancing a leader's hubris. Hum Relat 43:751-770

Klaussner S (2012) Trust and leadership: toward an interactive perspective. J Change Manag 12:417-439

Klaussner S (2014) Engulfed in the abyss: the emergence of abusive supervision as an escalating process of supervisor-subordinate interaction. Hum Relat 67:311-332 
Kramer RM (1999) Trust and distrust in organizations: emerging Perspectives, Enduring Questions. Annu Rev Psychol 50:569-598

Lavelle JJ, Rupp DE, Brockner J (2007) Taking a multifoci approach to the study of justice, social exchange, and citizenship behavior: the target similarity model. J Manag 33:841-866

Lazaric N, Denis B (2005) Routinization and memorization of tasks in a workshop: the case of the introduction of ISO norms. Ind Corp Change 14:873-896

Lewicki RJ, McAllister DJ, Bies RJ (1998) Trust and distrust: new relationships and realities. Acad Manag Rev 23:438-458

Loch CH, Sengupta K, Ahmad MG (2013) The microevolution of routines: how problem solving and social preferences interact. Organ Sci 24:99-115

Magee JC, Galinsky AD (2008) Social hierarchy: the self-reinforcing nature of power and status. Acad Manag Ann 2:351-398

Masterson SS, Lewis K, Goldman BM, Taylor MS (2000) Integrating justice and social exchange: the differing effects of fair procedures and treatment on work relationships. Acad Manag J 43:738-748

Mayer RC, Davis JH, Schoorman FD (1995) An integrative model of organizational trust. Acad Manag Rev 20:709-715

McAllister D (1995) Affect- and cognition-based trust as foundations for interpersonal cooperation in organizations. Acad Manag J 38:24-59

Mead GH (1934) Mind, self, and society from the standpoint oí a social behaviorist. University of Chicago Press, Chicago

Miller KD, Pentland BT, Choi S (2012) Dynamics of performing and remembering organizational routines. J Manag Stud 49:1536-1558

Molm LD, Takahashi N, Peterson G (2000) Risk and trust in social exchange: an empirical test of a classical proposition. Am J Sociol 105:1396-1427

Nelson RR, Winter SG (1982) An evolutionary theory of economic change. Belknap Press, Cambridge

Parmigiani A, Howard-Grenville J (2011) Routines revisited: exploring the capabilities and practice perspectives. Acad Manag Ann 5:413-453

Pearce CL, Conger JA, Locke EA (2008) Shared leadership theory. Leadersh Quart 19:622-628

Pearce CL, Hoch J, Jeppesen H, Wegge J (2010) New forms of management: shared and distributed leadership in organizations. Pers Psychol 9:151-153

Pentland BT, Feldman M (2005) Organizational routines as a unit of analysis. Ind Corp Change 14:793-815

Pentland BT, Feldman M, Becker MC, Liu P (2012) Dynamics of organizational routines: a generative model. J Manag Stud 49:1484-1508

Qing, M., Asif, M., Hussain, A., Jameel, A.: Exploring the impact of ethical leadership on job satisfaction and organizational commitment in public sector organizations: the mediating role of psychological empowerment. Rev. Manag. Sci. 1-28 (forthcoming)

Reynaud B (2005) The void at the heart of rules: routines in the context of rule-following. The case of the Paris Metro Workshop. Ind Corp Change 14:847-871

Robinson S (1996) Trust and the breach of the psychological contract. Adm Sci Q 41:574-599

Rousseau DM, Sitkin SB, Burt RS, Camerer C (1998) Not so different after all: a cross-discipline view of trust. Acad Manag Rev 23:393-404

Rupp D, Cropanzano R (2002) The mediating effects of social exchange relationships in predicting workplace outcomes from multifoci organizational justice. Organ Behav Hum Decis Process 89:925-946

Salvato C, Rerup C (2011) Beyond collective entities: multilevel research on organizational routines and capabilities. J Manag 37:468-490

Salvato C, Rerup C (2018) Routine regulation: balancing conflicting goals in organizational routines. Adm Sci Q 63:170-209

Sargis-Roussel C, Belmondo C, Deltour F (2017) Bringing people back in: how group internal social capital influences routines' emergence. Eur Manag Rev 14:101-112

Scandura TA, Schriesheim CA (1994) Leader-member exchange and supervisor career mentoring as complementary concepts in leadership research. Acad Manag J 37:1588-1602

Schoorman FD, Mayer RC, Davis JH (2007) An integrative model of organizational trust: past, present, and future. Acad Manag Rev 32:344-354

Sele K, Grand S (2016) Unpacking the dynamics of ecologies of routines: mediators and their generative effects in routine interactions. Organ Sci 27:722-738 
Simons TL, Peterson RS (2000) Task conflict and relationship conflict in top management teams: the pivotal role of intragroup trust. J Appl Psychol 85:102-111

Sonenshein S (2016) Routines and creativity: from dualism to duality. Organ Sci 27:739-758

Sparrowe RT, Liden RC (1997) Process and structure in leader-member exchange. Acad Manag Rev 22:522-552

Staw BM, Sanderlands LE, Dutton JE (1981) Threat-rigidity effects in organizational behavior: a multilevel analysis. Adm Sci Q 26:501-524

Tepper BJ (2000) Consequences of abusive supervision. Acad Manag J 43:178-190

Tepper BJ (2007) Abusive supervision in work organizations: review, synthesis, and research agenda. J Manag Inquiry 33:261-289

Tepper BJ, Moss SE, Lockhart DE, Carr JC (2007) Abusive supervision, upward maintenance communication, and subordinates' psychological distress. Acad Manag J 50:1169-1180

Thomas-Hunt MC, Ogden TY, Neale MA (2003) Who's really sharing? Effects of social and expert status on knowledge exchange within groups. Manage Sci 49:464-477

Thye SR (2000) A status value theory of power in exchange relations. Am Sociol Rev 65:407-432

Tripp TM, Bies RJ, Aquino K (2007) A Vigilante model of justice: revenge, reconciliation, forgiveness, and avoidance. Soc Justice Res 20:10-34

Tuckman BW (1965) Developmental sequences in small groups. Psychol Bull 63:384-399

Turner SF, Rindova V (2012) A balancing act: how organizations pursue consistency in routine functioning in the face of ongoing change. Organ Sci 23:24-46

Uhl-Bien M (2006) Relational leadership theory: exploring the social processes of leadership and organizing. Leadersh Q 17:654-676

Wang D, Waldman DA, Zhang Z (2014) A meta-analysis of shared leadership and team effectiveness. J Appl Psychol 99:181-198

Weber M (1978) Economy and society. In: Roth G, Wittich C (eds). Berkeley University of California Press, Berkley

Weber L, Carter A (1998) On constructing trust: temporality, self-disclosure, and perspective-taking. Int J Sociol Soc Policy 18:7-26

Weiler M, Hinz O (2019) Without each other, we have nothing: a state-of-the-art analysis on how to operationalize social capital. RMS 13:1003-1035

Wenzel M, Koch J, Cornelissen J, Rothmann W, Senf N (2019) How organizational actors live out paradoxiacal tensions through power relations: the case of a youth prison. Organ Behav Hum Decis Process 155:55-67

Wheelan SA, Johnston F (1996) The role of informal member leaders in a system containing formal leaders. Small Group Res 27:33-55

Whitener EM, Brodt SE, Korsgaard MA, Werner JM (1998) Managers as initiators of trust: an exchange relationship framework for understanding. Acad Manag Rev 23:513-530

Wright A (2019) Embodied organizational routines: explicating a practice understanding. J Manag Inquiry 28:153-165

Yoon W, Kim SJ, Song J (2016) Top management team characteristics and organizational creativity. RMS 10:757-779

Yukl G, Falbe CM (1990) Influence tactics and objectives in upward, downward, und lateral influence attempts. J Appl Psychol 75:132-140

Zapf D (2002) Emotion work and psychological well-being: a review of the literature and some conceptual considerations. Hum Resour Manag Rev 12:237-268

Zbaracki MJ, Bergen M (2010) When truces collapse: a longitudinal study of price-adjustment routines. Organ Sci 21:955-972

Publisher's Note Springer Nature remains neutral with regard to jurisdictional claims in published maps and institutional affiliations. 